\title{
Research Paper: Investigation of the Frequency of Foodborne Botulism in Patients Referred to Loghman Hospital in Tehran City, Iran, From 2008 to 2019
}


Reza Montazer Khorasan 5 , Alireza Jannani ${ }^{4}$ Q

1. Department of Pathobiology, School of Public Health, Tehran University of Medical Sciences, Tehran, Iran

2. Forensic Medicine Department, Shahid Beheshti University of Medical Sciences, Tehran, Iran.

3. Social Determinants of Health Research Center, Health Research Institute, Babol University of Medical Sciences, Babol, Mazandaran, Iran.

4. Infectious Diseases and Tropical Medicine Research Center, Shahid Beheshti University of Medical Sciences, Tehran, Iran.

5. Center for Communicable Disease Control, Ministry of Health and Medical Education, Tehran, Iran.

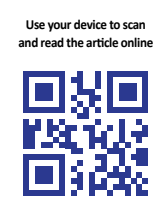

Cftation: Soltan Dallal MM, Najari F, Karbalaei Shabani A, Ezoji Kh, Shabani M, Montazer Khorasan MR, Jannani A. Investigation of the Frequency of Foodborne Botulism in Patients Referred to Loghman Hospital in Tehran City, Iran, From 2008 to 2019 International Journal of Medical Toxicology and Forensic Medicine. 2020; 10(2):28348. https://doi.org/10.32598/ijmtfm.v10i2.28348

https://doi.org/10.32598/ijmtfm.v10i2.28348

(ब) 03

Article info:

Received: 31 Dec 2019

First Revision: 05 Jan 2020

Accepted: 01 Feb 2020

Published: 20 Jun 2020

\section{Keywords:}

Clostridium, Botulism, Antitoxin, Food poisoning, Paralysis

\section{A B S T R ACT}

Background: Foodborne botulism is a fatal paralytic illness caused mainly by the neurotoxin produced by an anaerobic bacterium called Clostridium botulinum. In this study, the frequency of foodborne botulism in patients referred to a hospital in Iran has been reviewed for ten years.

Methods: In this routine database study, medical records of patients with foodborne botulism referred to Loghman Hospital in Tehran City, Iran, from March 20, 2008, to March 20, 2019 were reviewed. Information on variables of age, sex, place of residence, food consumed, clinical symptoms of patients (such as dysphagia, nausea, vomiting, ataxia, etc.), toxin type, and length of hospitalization were collected with a researcher-made questionnaire. Finally, the collected data were analyzed in SPSS-24 with descriptive and analytical statistical tests.

Results: In this study, 61 suspected botulism patients were clinically diagnosed in Loghman Hospital, of whom 55 patients were clinically suspected of foodborne botulism, 5 patients had iatrogenic botulism, and 1 patient had infant botulism. Of these 55 patients with the clinical diagnosis of foodborne botulism, 19 patients were confirmed by laboratory examinations, and 2 patients died. Sixteen patients confirmed by laboratory had neurotoxin botulinum type A. The mean age of the patients was 36.9 years with a standard deviation of 18.6 years. About $54.5 \%$ of the patients were male and $45.5 \%$ female. Weaknesses $(58.2 \%)$, ptosis (droopy eyelid) (56.4\%), and diplopia (double vision) (52.7\%) were the common clinical symptoms of the patients under study. Canned foods and dairy products were the main foods consumed by the patients. The duration of admission time ranged between 1 and 41 days, with an average of 7.7 days. About $23.64 \%$ of patients were admitted to the intensive care unit.

Conclusion: The prevalence of foodborne botulism is rare compared with other food poisonings but is still a major public health problem due to the consumption of traditional food products and unboiled canned foods in Iran.

* Corresponding Author:

Ahdie Karbalaei Shabani, $M A$.

Address: Department of Pathobiology, School of Public Health, Tehran University of Medical Sciences, Tehran, Iran.

Tel: +98 (912) 1371416

E-mail: ahdieshabani@yahoo.com 


\section{Introduction}

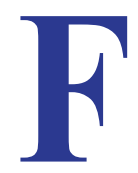

oodborne botulism is a fatal illness caused by the consumption of foods contaminated by the very potent neurotoxin botulinum. This neurotoxin is produced during the growth of anaerobic bacteria forming Clostridium botulinum spore and rarely by the species of Clostridium baratii and Clostridium butyricum as well $[1,2]$. The most common causes of foodborne botulism are incorrect methods of canning foods at home, inadequate baking, improper storage, and lack of adequate sanitation. Foodborne botulism symptoms usually occur 12 to 36 hours after the ingestion of foods contaminated with neurotoxins (A-G), but the first neurologic signs may suddenly appear in some cases [3].

Clostridium botulinum neurotoxins are the deadliest toxins among all toxic bacteria, animal and plant compounds, as well as chemical compounds, such that $30 \mathrm{mg}$ of the neurotoxin is potentially fatal $[4,5]$. There are seven known neurotoxins of botulism serotypes categorized from A to G. Almost most human cases of botulism are produced by types A, B, and E [6]. The main manifestations include flaccid muscle paralysis and cranial nerve palsy. Botulism, due to its high mortality, is a significant health problem [7]. Botulinum neurotoxin blocks acetylcholine receptors in neuromuscular connections, leading to a sudden descending paralysis of muscles. The first symptoms include ptosis (droopy eyelid), diplopia (double vision), and dysarthria (speech disorder), which eventually leads to complete body paralysis, including the respiratory muscles. While the affected patients are fully aware and maintain their sensory system during disease, this disease is fatal due to the involvement of respiratory muscles [8].

Diagnosis of botulism is made based on history, clinical examination, and laboratory confirmation by detecting the presence of toxins in food, serum, stool specimens, and gastric secretions [2,9]. However, the physician should not wait for lab results to begin treatment because of timely diagnosis and initiation of therapy can reduce the mortality rate of the disease [10]. Foodborne botulism in Iran due to the consumption of traditional food products and unpasteurized dairy products remains a public health challenge. Due to the importance and urgency of the treatment of foodborne botulism in the country, adequate information on the number of patients and its predominant types, as well as its main foodstuffs in different regions of the country, can be useful resources for managing the prevention of the disease. In this study, the frequency of foodborne botulism in patients referred to Loghman Hospital of Tehran in Iran has been reviewed in ten years from 2008 to 2019.

\section{Materials and Methods}

In this routine database study, the ten-year records of patients with foodborne botulism referred to Loghman Hospital, Tehran, Iran, were collected from 2008 to 2019. The sampling was done with a census method, and all samples were entered into the study according to inclusion and exclusion criteria. The inclusion criteria were all patients referred to Loghman Hospital of Tehran in Iran with a clinical diagnosis of botulism from March 20, 2008, to March 20, 2019. The exclusion criteria were patients with a final diagnosis of diseases other than botulism. Information on variables, including age, sex, place of residence, food consumed, clinical symptoms of patients (such as dysphagia, nausea, ptosis, diplopia, vomiting, ataxia, and so on), toxin type, and length of hospitalization were collected in a researcher-made questionnaire. All information about the name of physicians and patients were kept confidential, and the forms were completed anonymously. Finally, the obtained data were analyzed in SPSS 24 with descriptive and analytical statistical tests such as independent $t$ test and analysis of variance. In this study, a $P$ value of less than 0.05 was considered statistically significant.

\section{Results}

During this 10-year review period, a total of 61 patients with botulism were clinically diagnosed. Of these patients, 55 patients had foodborne botulism, 5 patients had iatrogenic botulism due to botox injection, and $1 \mathrm{pa}-$ tient had infant botulism. Thirty patients (54.5\%) were male, and 25 patients $(45.5 \%)$ were female. The number of deaths caused by foodborne botulism was two, and both were male. There was no statistically significant relationship between the status of patients at the time of discharge and gender $(\mathrm{P}>0.05)$. Also, the two deaths happened in 2010 and 2011. There was no statistically significant relationship between the outcome of the treatment and the year of admission time $(\mathrm{P}>0.05)$.

Of these 55 patients with the clinical diagnosis of foodborne botulism, 19 patients had positive laboratory results for foodborne botulism. Of these patients, 16 had botulinum neurotoxin type $\mathrm{A}$ in the results of toxin type. The mean age of the patients under study was 36.9 years, with a standard deviation of 18.6 years. The youngest patient was two years and the oldest 74 years. The highest number of patients (24 patients) was in the age group of 30-60 years, and the lowest number (1 patient) was 
Table 1. Symptoms and findings of botulism in 55 patients

\begin{tabular}{|c|c|}
\hline Signs and Symptoms & No. (\%) \\
\hline Limb weakness & $32(58.2)$ \\
\hline Ptosis & $31(56.4)$ \\
\hline Diplopia (double vision) & $29(52.7)$ \\
\hline Dysphagia & $28(50.9)$ \\
\hline Dysarthria (difficulty speaking) & $20(36.4)$ \\
\hline Nausea & $19(34.5)$ \\
\hline Body paralysis & $16(29.1)$ \\
\hline Respiratory problems & $16(29.1)$ \\
\hline Dizziness & $15(27.3)$ \\
\hline Disorder of consciousness (impaired consciousness) & $15(27.3)$ \\
\hline Vomiting & $14(25.5)$ \\
\hline Blurred vision & $14(25.5)$ \\
\hline Ataxia & $13(23.6)$ \\
\hline Fatigue & $11(20)$ \\
\hline Dry mouth & $4(7.3)$ \\
\hline Urinary incontinence & $2(3.6)$ \\
\hline Paresthesia & $1(1.8)$ \\
\hline
\end{tabular}

in the age group of 0-5 years. There was no statistically significant relationship between the age and laboratory diagnosis $(\mathrm{P}>0.05)$.

Regarding the location, the highest percentage of patients with $81.8 \%$ lived in urban areas, and those from rural regions included $18.2 \%$. There was no statistically significant relationship between the living place and laboratory diagnosis $(\mathrm{P}>0.05)$.

Regarding the clinical symptoms in our patients, weakness $(58.2 \%)$, ptosis (droopy eyelid) $(56.4 \%)$, and diplopia (double vision) (52.7\%) were the most common symptoms. Also, Table 1 presents a summary of other symptoms.

Regarding the foods consumed by the patients, canned foods with 31 cases and dairy products with 18 cases were the main foods consumed by patients. Among the consumed canned foods, canned fish with 24 cases was the most canned food, and among the consumed dairy products, locally produced cheese with 10 cases had the highest number of dairy products.

Regarding the treatment results, $96.4 \%$ of the patients were treated, and $3.6 \%$ died. Based on the results of laboratory diagnosis, $34.5 \%$ of the patient's test results were positive, $32.7 \%$ was negative, $30.9 \%$ of the test results were not in the patients' records, and $1.8 \%$ of the laboratory results were suspicious. According to the type of toxins, $29.1 \%$ of the patients had type A toxin.

Regarding the frequency distribution of study patients based on the year of admission time, the highest number of patients was admitted in the years 2010 and 2011 (with nine patients) and in 2015 and 2018 (with eight patients) and the lowest number of patients in 2014 with 1 case. Based on the statistical tests, there was a statistically significant relationship between the laboratory result of botulism and year of admission $(\mathrm{P}<0.05)$. 
Table 2. Frequency of the outbreaks of foodborne botulism in patients referred to Loghman Hospital from 2008-2019

\begin{tabular}{|c|c|c|c|c|c|}
\hline No. & Consumed Food & $\begin{array}{c}\text { Number of People } \\
\text { Involved in the } \\
\text { Outbreak }\end{array}$ & Year of Admission & Laboratory Diagnosis & $\begin{array}{c}\text { Clinical } \\
\text { Diagnosis }\end{array}$ \\
\hline 1 & Canned fish & 3 & 2009 & Request another sample & Botulism \\
\hline 2 & $\begin{array}{l}\text { Locally produced } \\
\text { cheese }\end{array}$ & 4 & 2010 & Toxin type A positive & Botulism \\
\hline 3 & Canned corn & 2 & 2010 & Toxin type A positive & Botulism \\
\hline 4 & $\begin{array}{l}\text { Locally produced } \\
\text { cheese }\end{array}$ & 4 & 2010 & Toxin type A positive & Botulism \\
\hline 5 & $\begin{array}{l}\text { Locally produced } \\
\text { cheese }\end{array}$ & 2 & 2011 & Toxin type A positive & Botulism \\
\hline 6 & $\begin{array}{l}\text { Locally produced } \\
\text { yogurt }\end{array}$ & 5 & 2014 & No specimens & Botulism \\
\hline 7 & Canned fish & 4 & 2015 & $\begin{array}{c}\text { One patient was sent } \\
\text { negative laboratory result }\end{array}$ & Botulism \\
\hline 8 & $\begin{array}{l}\text { Locally produced } \\
\text { cheese }\end{array}$ & 3 & 2016 & No specimens & Botulism \\
\hline 9 & Canned fish & 2 & 2016 & Negative laboratory result & Botulism \\
\hline 10 & $\begin{array}{l}\text { Locally produced } \\
\text { whey }\end{array}$ & 4 & 2018 & Toxin type A positive & Botulism \\
\hline
\end{tabular}

The highest number of patients (29.1\%) was in autumn, and according to the statistical tests, there was a statistically significant relationship between the laboratory results of botulism and the season $(\mathrm{P}<0.05)$. Also, the highest number of patients $(18.2 \%)$ was in December, and there was a statistically significant relationship between the laboratory results of botulism and the month of admission time $(\mathrm{P}<0.05)$. The mean hospital stay of the patients was 7.7 days, with a minimum of 1 day and a maximum of 41 days. Most patients (10 patients) were hospitalized for two days. About $23.64 \%$ of the study patients were admitted to the intensive care unit (ICU).

During the 10-year review period, there were ten outbreaks of foodborne botulism based on the clinical diagnosis. Based on the follow-up results in the Ministry of Health, five outbreaks were caused by neurotoxin type A, and six outbreaks by the use of traditional dairy products. However, in all these outbreaks, patients with a diagnosis of foodborne botulism were fully recovered by antitoxin treatment. The last outbreak was associated with the use of homemade whey contaminated with Clostridium botulinum neurotoxin type $\mathrm{A}$ in four members of a family in
September 2018 whose information is recorded in the Tehran University Medical Journal (Table 2).

According to the 10-year review study, the initial clinical diagnosis of some patients was other than botulism, for example, pneumonia, $\mathrm{CO}$ poisoning, myasthenia gravis, Guillain-Barré syndrome, and MS. Eventually, the final diagnosis of the foodborne botulism was made, and all patients were treated by antitoxin.

\section{Discussion}

Our study identified 55 patients with foodborne botulism among the patients admitted to Loghman Hospital during the ten years from 2008-2019, and the only type of toxin in the study was type A toxin, which showed a statistically significant relationship between the type of toxin and the year of hospitalization $(\mathrm{P}<0.05)$. There was no significant relationship between toxin type and age of the patients $(\mathrm{P}<0.05)$. According to the Ministry of Health report during the years 2011-2015, the dominant type of toxin was type A in our country, but types B and E have also been reported that are not consistent with our study [11]. 
It should be noted that due to the urgency of treatment for botulism, antitoxin injection is sometimes administered immediately after clinical suspicion, leading to false-negative results. As a result, botulism toxin types in the country are not properly identified, which has led to limitations in this study.

On the other hand, the clinical symptoms of botulism are similar to other diseases such as cerebrovascular disease, Guillain-Barré syndrome, myasthenia gravis, Miller Fisher syndrome, stroke, staphylococcus poisoning, tick paralysis, chemical poisoning (including carbon monoxide, barium carbonate, methyl chloride, methyl alcohol, organic phosphorus or atropine compounds), mushroom poisoning, drug reactions (including antibiotics such as neomycin, streptomycin, kanamycin or gentamicin), myocardial infarction, diphtheria, and mental illnesses. So at the time of diagnosis, botulism is less suspected because of its rarity $[12,13]$. Also, starting early treatments of botulism affects the results of mouse bioassay tests resulting in the lack of laboratory confirmation of botulism and detection of its types in our country. Over the ten-year review conducted in the present study, 9 patients were initially diagnosed with other diseases and then ultimately diagnosed with foodborne botulism. Therefore, it is one of the limitations of this study.

Foodborne botulism has remained a public health challenge in many societies using traditional foods [14]. Traditional foods in each region are often the leading cause of foodborne botulism in that geographical area. Previous studies have shown that botulism in Iran is primarily associated with the consumption of seafood and dairy products. Among dairy products, locally produced cheese was the main cause of botulism, primarily type A [15]. In the present study, canned foods with 31 cases and dairy products, with 18 cases, were the most consumed foods. Also, locally produced cheese with 10 cases was the most dairy products causing foodborne botulism. This finding has been confirmed by the previous studies.

In previous reviews conducted in Iran, the number of men with botulism was reported higher than women, and their mean age was 22.35 years [16]. Also, in previous studies in Iran, locally produced cheese was the most common food causing botulism, and neurotoxin type A was the highest neurotoxin found in patients [16, 17]. Also, in our review, the mean age of the patients was 36.9 years, the number of men was higher than that of women, and dairy products followed by canned foods were the most consumed foods. However, in some studies, the toxin type $\mathrm{E}$ was the most common type of toxin [18]. This finding is not consistent with the findings of our research. The highest frequency of patient referral in this study was in autumn. This result is consistent with the previous results of the Imam Reza Hospital in Mashhad City, Iran [19].

Botulism can be fatal, and its clinical diagnose is difficult in elderly patients. There is usually some uncertainty about the diagnosis and treatment of botulism. On the other hand, antitoxin injection only prevents the symptoms and does not treat the developed paralytic symptoms. The immediate early clinical diagnosis and antitoxin injection in the early hours of the illness can save people from this fatal disease by preventing the progression of paralysis and respiratory failure. Patients who do not receive antitoxin within 12 hours after getting botulism are three times more likely to develop respiratory failure, which is the leading cause of disease mortality [20].

On the other hand, laboratory results for botulism are time-consuming regarding the standard method of botulism detection, which is the mouse bioassay method [21]. Therefore, the detection of botulism is based on a clinical examination and confirmation by laboratory testing $[22,23]$. In the meantime, the possibility of botulism should be considered in patients with a history of consuming canned foods or traditional foods prepared at home and symptoms such as the sudden onset of symmetric descending flaccid paralysis, blurred vision with general weakness, ptosis (droopy eyelid), diplopia (double vision), dry mouth, dysphagia, dysphonia, dysarthria (speech disorder), no fever (in the absence of secondary infection), nausea, vomiting, and pupillary dilatation. On the other hand, suspicious specimens should be sent immediately to the Botulism Laboratory of Bacteriology Department of Pasteur Institute of Iran for diagnosis within 24 hours before administration of antitoxin (because antitoxin counteracts all toxins circulating in the blood). If the samples are positive, an instant report of botulism should be made to determine the source of the infection and identify other infected people according to the national guidelines. Eventually, patients with botulism will fully recover if they receive antitoxin and supportive care [23]. As in this study, $96.4 \%$ of the patients under investigation were fully recovered with a timely diagnosis of the disease, treatment with antitoxin, and supportive therapies.

\section{Conclusion}

The prevalence of foodborne botulism is very low compared to other food poisonings but is still a major public 
health problem due to the consumption of traditional food products and unboiled canned foods in our country.

\section{Ethical Considerations}

\section{Compliance with ethical guidelines}

This article is extracted from a research project by the Food Microbiology Research Center of Tehran University of Medical Sciences (Code: 39077). All ethical principles were considered in this article.

\section{Funding}

This research did not receive any specific grant from funding agencies in the public, commercial, or not-forprofit sectors.

\section{Author's contributions}

All authors contributed to design and to run all parts of the research.

\section{Conflict of interest}

The authors declared no conflict of interest.

\section{Acknowledgements}

The authors are grateful for the material and spiritual support of the Vice-Chancellor for Research. We also express our gratitude and appreciation to the Clinical Research Development Unit of Loghman Hakim Hospital of Shahid Beheshti University of Medical Sciences, Tehran, Iran, for their support and cooperation during the study period.

\section{References}

[1] Lindstrom M, Kiviniemi K, Korkeala H. Hazard and control of group II (non-proteolytic) Clostridium botulinum in modern food processing. Int J Food Microbiol. 2006; 108(1):92-104. [DOI:10.1016/j.ijfoodmicro.2005.11.003] [PMID]

[2] Espelund M, Klaveness D. Botulism outbreaks in natural environments - an update. Front Microbiol. 2014; 5:287. [DOI:10.3389/ fmicb.2014.00287] [PMID] [PMCID]

[3] Forss N, Ramstad R, Bäcklund T, Lindström M, Kolho E. Difficulties in diagnosing food-borne botulism. Case Rep Neurol. 2012 4(2):113-5. [DOI:10.1159/000339736] [PMID] [PMCID]

[4] Peck MW. Clostridium botulinum and the safety of minimally heated, chilled foods: An emerging issue? J appl Microbiol. 2006; 101(3):556-70. [DOI:10.1111/j.1365-2672.2006.02987.x] [PMID]
[5] Poulain B, Popoff MR. Why are botulinum neurotoxin-producing bacteria so diverse and botulinum neurotoxins so toxic? Toxins (Basel). 2019; 11(1). pii: E34. [DOI:10.3390/toxins11010034] [PMID] [PMCID]

[6] Horowitz BZ. Type E botulism. Clin Toxicol Phila. 2010; 48(9):88095. [DOI:10.3109/15563650.2010.526943] [PMID]

[7] Rafie S, Salmanzadeh S, Mehramiri A, Nejati A. Botulism outbreak in a family after ingestion of locally produced cheese. Iran J Med Sci. 2017; 42(2):201-4. https://www.ncbi.nlm.nih.gov/pubmed/28360447

[8] Shapiro RL, Hatheway C, Swerdlow DL. Botulism in the United States: A clinical and epidemiologic review. Ann Intern Med. 1998; 129(3):221-8. [DOI:10.7326/0003-4819-129-3-19980801000011] [PMID]

[9] Proverbio MR, Lamba M, Rossi A, Siani P. Early diagnosis and treatment in a child with foodborne botulism. Anaerobe. 2016; 39:189-92. [DOI:10.1016/j.anaerobe.2015.12.002] [PMID]

[10] Shrivastava SR, Shrivastava PS, Ramasamy J. Preventing the outbreaks of foodborne botulism and minimizing the risk of fatality. Ann Trop Med PH. 2017; 10(5):1360-1. [DOI:10.4103/17556783.196826]

[11] Montazer Khorasan MR, Rahbar M, Zahedi Bialvaei A, Gouya MM, Shahcheraghi F, Eshrati B. National surveillance of foodborne botulism in Iran during 2011-2015. Rev Med Microbiol 2020; 31(1):42-6. https://journals.lww.com/revmedmicrobiol/ Citation/2020/01000/National_surveillance_of_food_borne_botulism_in.5.aspx

[12] Hughes JM, Blumenthal JR, Merson MH, Lombard GL, Dowell VR Jr, Gangarosa EJ. Clinical features of types A and B foodborne botulism. Ann Intern Med. 1981; 95(4):442-5. [DOI:10.7326/00034819-95-4-442] [PMID]

[13] Botulism in the United States, 1899-1996: Handbook for epidemiologists, clinicians, and laboratory workers. Centers for Disease Control and Prevention. Atlanta, Ga: 1998. https://stacks.cdc. gov/view/cdc/6673/

[14] Hauschild A, Gauvreau L. Food-borne botulism in Canada, 1971-84. Can Med Assoc J. 1985; 133(11):1141-6. https://www. ncbi.nlm.nih.gov/pmc/articles/PMC1346371/

[15] Shahcheraghi F, Nobari S, Vahdani P, Majdian J, Aslani MM [Type A botulism in members of a family following the consumption of locally made cheese (Persian)]. J Mazand Univ Med Sci. 2013; 22(96):124-9. https://www.magiran.com/ paper/1233080/?lang=en

[16] Nejadrahim R, Delirrad M. Foodborne Botulism: A study of 57 cases in Northwest Iran. Iran J Toxicol. 2016; 10(6):45-50 [DOI:10.29252/arakmu.10.6.45]

[17] Pourshafie MR, Saifie M, Shafiee A, Vahdani P, Aslani M, Salemian J. An outbreak of foodborne botulism associated with contaminated locally made cheese in Iran. Scand J Infect Dis. 1998; 30(1):92-4. [DOI:10.1080/003655498750002385] [PMID]

[18] Nobari S, Aslani M, Masoumi-Asl H, Vahdani P, Shouraj F, Shahcheraghi F. [Botulism in Iran, 2004-2010 (Persian)]. Paper presented at: $20^{\text {th }}$ Iranian Congress of Infectious Diseases and Tropical Medicine. 2011; Tehran, Iran.

[19] Habibiyan Nejad Z, Afshari R. Foodborne Botulism in Mashhad from 2003 to 2010. J Clinic Toxicol. 2011; 1(3):1-4. https:/ / www. 
longdom.org/abstract/foodborne-botulism-in-mashhad-from2003-to-2010-47971.html

[20] Sandrock CE, Murin S. Clinical predictors of respiratory failure and long-term outcome in black tar heroin-associated wound botulism. Chest. 2001; 120(2):562-6. [DOI:10.1378/chest.120.2.562] [PMID]

[21] Sharma SK, Whiting RC. Methods for detection of Clostridium botulinum toxin in foods. J Food Prot. 2005; 68(6):1256-63. [DOI:10.4315/0362-028X-68.6.1256] [PMID]

[22] Sobel J. Botulism. Clin Infect Dis 2005; 41(8):1167-73. [DOI:10.1086/444507] [PMID]

[23] Anniballi F, Lonati D, Fiore A, Auricchio B, De Medici D, Locatelli CA. New targets in the search for preventive and therapeutic agents for botulism. Expert Rev Anti Infect Ther. 2014; 12(9):107586. [DOI:10.1586/14787210.2014.945917] [PMID] 
This Page Intentionally Left Blank 